On the Determinacy of Monetary Policy under Expectational Errors

Jagjit S. Chadha and Luisa Corrado

May 2007

CWPE 0722 


\title{
On the Determinacy of Monetary Policy under Expectational Errors*
}

\author{
Jagjit S. Chadha ${ }^{\dagger}$ \\ BNP Paribas \\ Luisa Corrado $\ddagger$ \\ University of Cambridge and University of Rome Tor Vergata
}

May 1, 2007

\begin{abstract}
Forward looking agents with expectational errors provide a problem for monetary policy. We show that under such conditions a standard interest rate rule may not achieve determinacy. We suggest a modification to the standard policy rule that guarantees determinacy in this setting, which involves the policy maker co-ordinating inflation dynamics by responding to each of past, current and expected inflation. We show that this solution maps directly into Woodford's (2000) timeless perspective. We trace the responses in an artificial economy and illustrate the extent to which macroeconomic persistence is reduced following the adoption of this rule.

JEL classification: C62; E31; E58.

Keywords: Expectational Errors; Indeterminacy; Monetary Policy Rules.

${ }^{*}$ We thank Andrew Blake, Martin Ellison, Sean Holly, Seppo Honkapohja, Andrew Hughes Hallett, George Kapetanios, Charles Nolan, Bill Poole and Robert Rasche, graduate students at the University of Cambridge, seminar participants at the CDMA at St. Andrews University, Queen Mary College London, Kent University, Deutsche Bundesbank, Central Bank of Iceland, Norges Bank, Cambridge University, the Italian CNR-FIRB and to participants of the Royal Economic Society Conference 2006 at Nottingham University for helpful comments. This paper was first circulated under the title: 'Sunspots and Monetary Policy'.

$\dagger$ BNP Paribas, 10 Harewood Avenue, Marylebone, London NW1 6AA. E-mail: jagjit.chadha@bnpparibas.com. Visiting Professor of Economics at the University of Kent

$\ddagger$ Address for Correspondence. Faculty of Economics and CIMF, Cambridge University, CB3 9DE, Cambridge, UK. e-mail: lc242@econ.cam.ac.uk. Phone +44-1223-335284.
\end{abstract} at Canterbury. 


\section{Introduction}

The question of how to control an economy in which agents base their current behavior on forward-looking expectations has recently preoccupied monetary theorists and policy-makers. In this setting, the main stabilization device appears to be predictable monetary policy rules, which act to contain destabilizing expectations. Woodford (2005) has gone as far to argue that: 'not only do expectations about policy matter, but, at least under current conditions, very little else matters' (p. 3). In this paper we consider the problem of how to set policy when those expectations are detached from fundamentals.

The academic literature has considered how active policy rules make economies prone to unintended equilibrium outcomes, such as a liquidity trap (Benhabib et al, 2002). It has also shown how forward-looking models of inflation and output may lead to chaotic dynamics and to indeterminacy (for example, Benhabib et al, 2001, 2004). To avoid indeterminacy Woodford (2003a) has argued that the authorities should adopt a rule where nominal interest rates respond more than equiproportionally to expected inflation (see also Chari et al, 1998 and Schmitt-Grohè and Uribe, 2000). From a theoretical point of view such rules may be reasonable approximations of optimal feedback rules (see Bernanke and Woodford, 1997 and Clarida et al, 2000). But Batini and Pearlman (2002) show that a heavily forwardlooking rule may not be sufficient to rule out indeterminacy as reacting to events that lie far in the future may generate multiple equilibria and dynamic instability. ${ }^{1}$

The challenge of designing rules to control expectations has been taken up by policy-makers, for example King (2005), ${ }^{2}$ Bernanke $(2003)^{3}$ and

\footnotetext{
${ }^{1}$ Batini and Pearlman (2002) use interchangeably the term indeterminate equilibria or sunspot equilibria to identify cases where multiple solutions to the model depend either on extraneous random variables (sunspot) or on more fundamental shocks. Chadha (2007) also considers the cases where fiscal policy can threaten the ability of a monetary rule to achieve determinacy.

${ }^{2} \mathrm{He}$ stresses the impact of policy rules on expectation formation: 'A key motivation for the study of monetary policy rules was the insight that if economic agents base their decisions on expectations of the future then the way monetary policy is expected to be conducted in the future affects economic outcomes today. Hence it is very important to think about how policy influences the expectations of the private sector' (p. 5).

${ }^{3}$ Bernanke (2003) argues that: 'The central bank must also maintain a strong commitment to keeping inflation -and, hence, public expectations of inflation- firmly under control. Because monetary policy influences inflation with a lag, keeping inflation under control may require the central bank to anticipate future movements in inflation and move preemptively. Hence constrained discretion is an inherently forward-looking
} 
Trichet (2005). Recently Trichet (2005) has taken this point further and looked at the implications for monetary policy of misled inflation expectations, that is expectations that are dislodged from economic fundamentals, and suggests that 'misled market expectations can amplify and prolong the dynamic response of inflation and real activity to an inflationary or deflationary shock of sufficiently great potency' (p. 3).

Given the importance of this ongoing policy debate, we consider a policy rule that is not only designed to stabilize expectations tied to fundamentals, as in the canonical literature, but also to control for expectational errors that are not. For our purposes, we may motivate expectational errors from the possibility that agents may have theories of inflation determination that differ from the model used by policy-makers or that there is systematic heterogeneity across agents in forming inflation expectations (see Ireland, 2003; Mankiw, Reis and Wolfers, 2003).

Expectational errors may lead to indeterminacy of a rational expectation solution and a number of papers have considered how to ensure stability in this setting (see Farmer, Waggoner and Zha, 2006). Orphanides and Williams (2005) show that when there are expectational errors, but the process for inflation is learnable, a rise of private inflation expectations beyond those implied by perfect knowledge can be resolved by a forecastbased rule with a more aggressive response than could be expected in normal conditions. In this case expectational errors could gradually be learnt away. ${ }^{4}$

Carlstrom and Fuerst (2001) have noted that when the economy is subject to expectational errors, but the process of inflation is not learnable, a backward-looking component in the policy rule could rule out indeterminacy. Such policy commits the Central Bank to move future policy rates in response to today's inflationary momentum. This commitment corrects over time the drift in inflation that would otherwise be induced by following inflation expectations alone. This timing difference is crucial as the monetary authorities do not move until long after the public has moved. So one suggestion is to target previous inflation errors in order to give an anchor to monetary policy. And in the real world it may be difficult to distinguish between an economy driven by a non-fundamental shock only and an economy driven by both fundamental and non-fundamental shocks. Beyer and Farmer (2003) have shown that such economies lead to observationally equivalent reduced form models, which means that the policy-makers cannot

policy approach' (p. 1).

${ }^{4}$ For an analysis of the interaction between sunspots, monetary policy and learning in New-Keynesian models see also Carlstrom and Fuerst (2004) and Honkapohja and Mitra (2004) 
rule out by observation alone, the possibility of expectational errors in inflation.

In this paper, we find that responding to each of past, current and expected inflation acts to co-ordinate inflation through time so that unstable dynamics do not emerge. Specifically, we find that by just targeting one or two of past, current or expected, the system remains dominated by expectational errors. We can illustrate with some simple examples. Suppose there are persistently positive expectational errors and these are targeted by the central bank, as an indicator of future inflation. Policy rates will then rise and there will be a surprise deflation for agents who face higher than expected real rates. If expectational errors remain elevated then output will continue to fall as real rates remain high. Such an economy will only be stabilized if the central bank ratifies the agents' raised inflation expectations by cutting interest rates. If, however, the central banks acts solely on past inflation then it will find itself continually trying to catch-up with a process in which agents' expectational errors drive the system. We find that by targeting past policy errors, responding to current inflation and by taking into account inflation expectations, then policy makers can stabilize this system in spite of the presence of persistent expectational errors.

To derive the optimal policy response in presence of expectational errors, we design the rule in two stages: first, we write a history dependent rule, which is dynamically consistent (Woodford, 2000). ${ }^{5}$ The timeless targeting rule applies the same first order conditions for inflation and output in each time period and ignores any start-up conditions. This feature implies that there is no change in the constraints operating on the central bank model and hence no dynamic inconsistency. The second stage requires the expectational error to be expressed as a function of fundamental shocks and are thus restricted to eradicate expectational errors. Following the suggestion of Evans and Honkapohja (2006), the monetary authorities should therefore condition their policy action on the structural equations of the model characterizing fundamental shocks and endogenous variables. ${ }^{6}$ We find that if the central bank commits itself to set interest rates in

\footnotetext{
${ }^{5}$ Woodford (2005) writes on the superiority of history dependent rules over "let bygones be bygones" rules: 'In general the most effective policy (the best outcome from among the set of possible rational-expectations equilibria) requires that policy be conducted in a history dependent way, so that policy at any time depends not only on conditions then (and what it is considered possible to achieve from then on), but also on past conditions, even though these no longer constrain what it is possible to achieve in the present' (p.7). See also McCallum and Nelson's (2004) clear exposition of the same point.

${ }^{6}$ Evans and Honkapohja (2006) show that right amount of response to expectations also yields determinacy and learnability.
} 
accordance with a Past-Current-Expected (PCE) rule, then the rational expectation equilibrium of a forward-looking system with expectational errors is necessarily determinate.

The paper is organized as follows. Section 2 shows how expectational errors lead to indeterminacy of the solution. Section 3 shows how an expectational errors can be eliminated by appropriate use of a PCE policy rule. Section 4 examines the local determinacy region of the system solution and illustrates policy experiments on a standard New-Keynesian models with inflation forecast errors. Section 5 concludes.

\section{Expectational errors and determinacy}

Let us consider the following companion form representation for $\mathbf{X}_{t}=$ $\left[x_{t}, E_{t} x_{t+1}\right]^{\prime}$, given some variable $x_{t}$ :

$$
\mathbf{A X}_{t}=\mathbf{B} \mathbf{X}_{t-1}+\mathbf{\Psi} \omega_{t}
$$

Where $\mathbf{A}, \mathbf{B}$ and $\boldsymbol{\Psi}$ are conformable matrices and $\omega_{t}$ is an expectational error:

$$
\omega_{t}=x_{t}-E_{t-1} x_{t},
$$

defined as the difference between the actual value of $x_{t}$ and its expectation, $E_{t-1} x_{t}$.

The reduced form of (1) is:

$$
\mathbf{X}_{t}=\mathbf{A}^{-1} \mathbf{B} \mathbf{X}_{t-1}+\mathbf{A}^{-1} \mathbf{\Psi} \omega_{t}
$$

where given the form of $\mathbf{A}^{-1} \mathbf{B}$ the system may be indeterminate. The policy problem is to render the system determinate by adopting a rule, some matrix $\mathbf{K}$, which acts on $\mathbf{X}_{t-1}=\left[x_{t-1}, E_{t-1} x_{t}\right]^{\prime}$

$$
\mathbf{U}_{t}=\mathbf{K X}_{t-1}
$$

We now introduce the control variable $\mathbf{U}_{t}$ in the original system (1):

$$
\mathbf{X}_{t}=\mathbf{A}^{-1} \mathbf{B} \mathbf{X}_{t-1}+\mathbf{D} \mathbf{U}_{t}+\mathbf{A}^{-1} \mathbf{\Psi} \omega_{t}
$$

where $\mathbf{D}$ is conformable matrix for $\mathbf{U}_{t}$. By replacing in (5) the rule defined in (4) the reduced form model can be rewritten as:

$$
\mathbf{X}_{t}=\mathbf{C X}_{t-1}+\mathbf{A}^{-1} \mathbf{\Psi} \omega_{t}
$$


where $\mathbf{C}=\left[\mathbf{A}^{-\mathbf{1}} \mathbf{B}+\mathbf{D K}\right]$ is the stability matrix for the system in $\mathbf{X}_{t}$.

Proposition $\mathbf{1}$ The system $\left[\mathbf{A}^{-\mathbf{1}} \mathbf{B}, \mathbf{D}\right]$ is said to be stabilizable if there exists a matrix $\mathbf{K}$ such that $\mathbf{A}^{-\mathbf{1}} \mathbf{B}+\mathbf{D K}$ is a stabilty matrix for $\mathbf{X}$. This implies that $\mathbf{X}_{t} \rightarrow 0$ as $t \rightarrow \infty$.

We can say that $\mathbf{C}$ is a stability matrix if the number of eigenvalues of C inside or outside the unit circle, in the complex plane, correspond to the number of predetermined and jump variables in the vector of endogenous variables, $\mathbf{X}_{t}$ (see Blanchard and Khan, 1980). Any further endogenous variables which are a function of $\mathbf{X}_{t}$ will also be stabilized by $\mathbf{C}$.

\subsection{A simple model for inflation}

Now consider a system in which there is forward-looking behavior and expectational errors, for example, a standard forward-looking inflation equation:

$$
\pi_{t}=\beta E_{t} \pi_{t+1}
$$

where $\pi_{t}$ is current inflation and $E_{t} \pi_{t+1}$ is expected inflation based on information at time $t$. As in Beyer and Farmer (2003) we impose the general parameter restriction $|\beta|>0$ on the discount factor.

Now consider the difference between actual, $\pi_{t}$, and expected inflation $E_{t-1} \pi_{t}$

$$
\pi_{t}-E_{t-1} \pi_{t}=\omega_{t}
$$

where there is an expectational error, $\omega_{t}$ (Lubik and Schorfheide, 2003 and Beyer and Farmer, 2003). As people may have theories of inflation determination that differ from the true model (Ireland, 2003) or that disagree with each other (Mankiw, Reis and Wolfers, 2003) we could think of (7) as a representing any alternate theory of inflation determination.

In companion form (6) and (7) are:

$$
\left[\begin{array}{cc}
1 & -\beta \\
1 & 0
\end{array}\right]\left[\begin{array}{c}
\pi_{t} \\
E_{t} \pi_{t+1}
\end{array}\right]=\left[\begin{array}{ll}
0 & 0 \\
0 & 1
\end{array}\right]\left[\begin{array}{c}
\pi_{t-1} \\
E_{t-1} \pi_{t}
\end{array}\right]+\left[\begin{array}{l}
0 \\
1
\end{array}\right] \omega_{t}
$$

Proposition 2 A forward-looking system with expectational errors is prone to indeterminacy. 
In order to give a simple proof of the above proposition we verify the conditions listed in Appendix A for the existence of a saddle point equilibrium exist.

Given the reduced form representation (1) with $\mathbf{X}_{t}=\left[\pi_{t}, E_{t} \pi_{t+1}\right]^{\prime}$ we calculate $\mathbf{A}^{-1}$ simply to give:

$$
\mathbf{A}^{-1}=\left[\begin{array}{cc}
0 / \beta & -\beta /-\beta \\
-1 / \beta & 1 / \beta
\end{array}\right]=\left[\begin{array}{cc}
0 & 1 \\
-\beta^{-1} & \beta^{-1}
\end{array}\right]
$$

hence,

$$
\mathbf{X}_{t}=\left[\begin{array}{cc}
0 & 1 \\
0 & \beta^{-1}
\end{array}\right] \mathbf{X}_{t-1}+\left[\begin{array}{c}
0 \\
\beta^{-1}
\end{array}\right] \omega_{t}
$$

The roots of system (10) are equal to zero and $\beta^{-1}$, so there are insufficient explosive roots to determine uniquely the endogenous variables of the model. So, this system as it stands has no unique rational expectations equilibrium (for a similar proof, see Beyer and Farmer, 2003).

To illustrate how the absence of a proper control rule in a forwardlooking system with expectational errors may lead to a drift in inflation, we simulate the process for inflation described by (8), ${ }^{7}$ where the dynamics for inflation, $\pi_{t}$, are written as a function of the expectational error, $\omega_{t}$. To make the process comparable with US experience we derive expectational errors as the difference between year on year inflation calculated on US consumer price inflation and one-year inflation expectations from the Michigan Survey over the years 1979-2006. ${ }^{8}$ The three panels of Figure 1 shows the simulated inflation from the solution of (8) plotted against actual inflation in each of three sub-periods: 1979-1989, 1990-1999 and from 2000-2006. In the first period, the range for actual inflation is around $12 \%$ but for the simulated series it is around $35 \%$ i.e. around 3 times the observed. In the middle panel, the range for inflation is around $4 \%$ and for the simulated series it is around $25 \%$ and in the bottom panel we can see that the ranges fall to $2 \%$ and $15 \%$, respectively. So it would seem that the simulations project greater inflation variance, on the basis of inflation expectational errors, than we actually observe and that this tendency increases through time i.e. the ratio of the simulated and actual inflation series rises. This is not to argue necessarily

\footnotetext{
${ }^{7}$ In order to simulate the process for inflation we set the initial value for the inflation to the actual level of US inflation.

${ }^{8}$ We use the US Consumer Prices (all items less food and energy), seasonally adjusted by the BLS. The Michigan Survey commenced in 1948 and provides a survey on expected inflation. More than 500 respondents, solicited by telephone, are asked to provide quantitative, point estimates of expected inflation.
} 

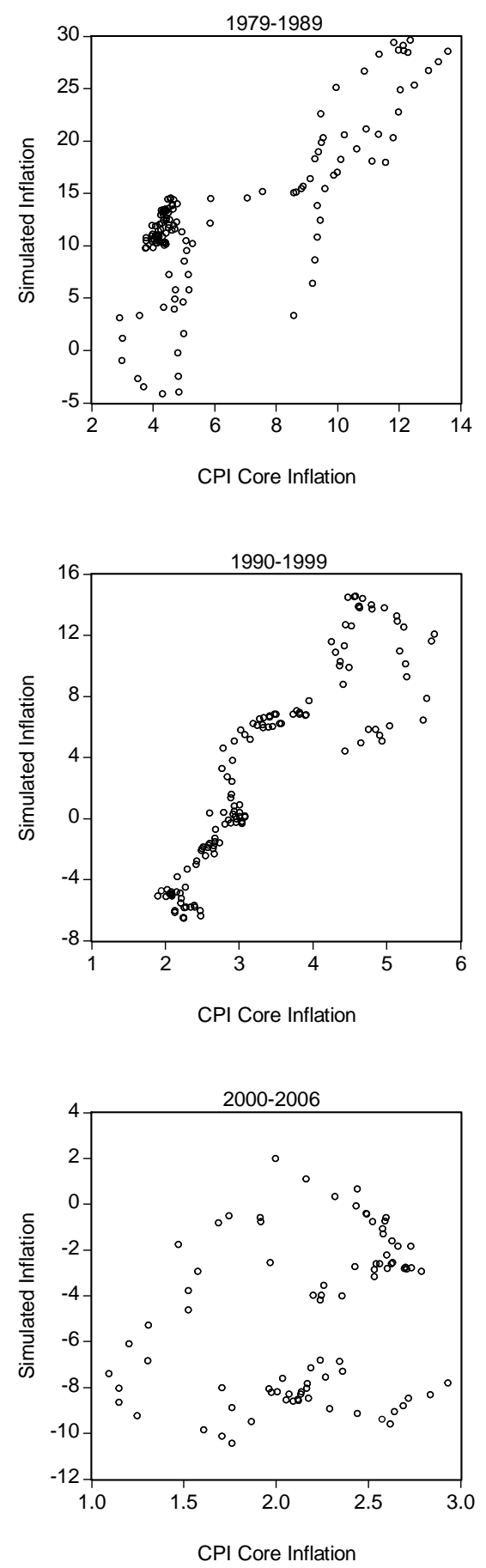

8

Figure 1: Inflation with Non-Fundamental Shocks and an Indeterminate Policy Rule 
that the policy rules have altered to produce a more stable inflation process but it would seem that the contribution of inflation expectational errors to the inflation process has somehow been mitigated. In the following section we show how it is possible to stabilize the solution for inflation with a policy rule that responds to the history of expectational errors.

\subsection{Expectational errors with a policy rule}

We examine how policy can act to bring about a unique rational expectations equilibrium. We model policy as simply acting on any or all of lagged, current or expected inflation. ${ }^{9}$ Appendix B shows that in all these cases the policy rule does not lead to an unique rational expectations equilibrium. In the next section though we show that it is possible for policy to introduce stability and determinacy but that in the presence of expectational errors policy must act against all of past, current and future inflation plus the fundamental inflation shock.

\subsubsection{Past, current and expected inflation}

Let us first consider the following forward-looking model for inflation:

$$
\pi_{t}=\beta E_{t} \pi_{t+1}+k y_{t}+v_{t}^{\pi}
$$

where the parameter $k>0, v_{t}^{\pi}$ is a supply shock that satisfies $E_{t-1} v_{t}^{\pi}=0$ and $y_{t}$ is aggregate demand:

$$
y_{t}=-\left(i_{t}-E_{t} \pi_{t+1}\right)
$$

which depends on the real interest rate $i_{t}-E_{t} \pi_{t+1}$.

We now consider a general form of the problem where the policy rate, $i_{t}$, acts against past, current and expected inflation (PCE) and the inflation shock in equal measure:

$$
i_{t}=\phi E_{t} \pi_{t+1}+\phi \pi_{t}-\phi \pi_{t-1}+\phi v_{t}^{\pi} .
$$

Setting $k=1$ and replacing (13) and (12) in (11) the inflation equation can be rewritten as:

\footnotetext{
${ }^{9}$ Bullard and Mitra (2002) also study macroeconomic systems with forward-looking private sector agents and a monetary authority that is trying to control the economy through the use of a linear policy rule. However, they use stability under recursive learning as a criterion for evaluating monetary policy rules in this context.
} 


$$
\pi_{t}=(1+\beta-\phi) E_{t} \pi_{t+1}-\phi \pi_{t}+\phi \pi_{t-1}+(1-\phi) v_{t}^{\pi} .
$$

Let us keep the expectational error in inflation given by (7). In companion form (14) and (7) are:

$$
\begin{aligned}
& {\left[\begin{array}{cc}
(1+\phi) & -(1+\beta-\phi) \\
1 & 0
\end{array}\right]\left[\begin{array}{c}
\pi_{t} \\
E_{t} \pi_{t+1}
\end{array}\right]=} \\
& {\left[\begin{array}{ll}
\phi & 0 \\
0 & 1
\end{array}\right]\left[\begin{array}{c}
\pi_{t-1} \\
E_{t-1} \pi_{t}
\end{array}\right]+\left[\begin{array}{cc}
(1-\phi) & 0 \\
0 & 1
\end{array}\right]\left[\begin{array}{c}
v_{t}^{\pi} \\
\omega_{t}
\end{array}\right] .}
\end{aligned}
$$

and the reduced form system is:

$$
\begin{aligned}
{\left[\begin{array}{c}
\pi_{t} \\
E_{t} \pi_{t+1}
\end{array}\right]=} & {\left[\begin{array}{cc}
0 & 1 \\
-\frac{\phi}{(1+\beta-\phi)} & \frac{(1+\phi)}{(1+\beta-\phi)}
\end{array}\right]\left[\begin{array}{c}
\pi_{t-1} \\
E_{t-1} \pi_{t}
\end{array}\right]+} \\
& {\left[\begin{array}{cc}
0 & 1 \\
-\frac{(1-\phi)}{(1+\beta-\phi)} & \frac{(1+\phi)}{(1+\beta-\phi)}
\end{array}\right]\left[\begin{array}{c}
v_{t}^{\pi} \\
\omega_{t}
\end{array}\right] . }
\end{aligned}
$$

If the equilibrium is unique, as in Beyer and Farmer (2003), there must be one unstable root that allows to pin down the non predetermined variable $E_{t} \pi_{t+1}$ as a function of the lagged state variable $\pi_{t-1}$ and the fundamental shock, $v_{t}^{\pi}$.If the equilibrium is unique the non-fundamental shock, $\omega_{t}$, will be determined endogenously as a function of $v_{t}^{\pi}$. First, we examine whether the conditions for a saddle-point equilibrium exist in this case. We see that $\operatorname{det}\left(\mathbf{A}^{-1} \mathbf{B}\right)=\frac{\phi}{(1+\beta-\phi)}$ and $\operatorname{tr}\left(\mathbf{A}^{-1} \mathbf{B}\right)=\frac{(1+\phi)}{(1+\beta-\phi)}$. As the trace is positive we verify that the conditions listed in Appendix A for the existence of a saddle point equilibrium exist:

$$
\operatorname{det}\left(\mathbf{A}^{-1} \mathbf{B}\right)-\operatorname{tr}\left(\mathbf{A}^{-1} \mathbf{B}\right)=\frac{-1}{(1+\beta-\phi)}<-1 \text { if } \phi>\beta .
$$

In addition:

$$
\operatorname{det}\left(\mathbf{A}^{-1} \mathbf{B}\right)+\operatorname{tr}\left(\mathbf{A}^{-1} \mathbf{B}\right)=\frac{2 \phi+1}{(1+\beta-\phi)}>-1,
$$

which is always true if $\phi>\beta$. So if the feedback rule coefficient on past, current and expected inflation is higher than $\beta$, the system is regular. The following proposition follows: 
Proposition 3 In the presence of expectational errors the policy rule may be required to respond to each of past, current and expected (PCE) inflation in order to stabilize inflation.

In order to ensure the regularity of the system in the presence of expectational errors, the policy rule must be respond to previous errors but also pay attention to current inflation and expectations, which may result from fundamental shocks. ${ }^{10}$

We now turn to analyze how well the inflation process implied by (16), under stability, tracks the observed inflation data for the US. As in the previous example, ${ }^{11}$ we express (16) as a function of the non-fundamental error, $\omega_{t}$. Again we derive expectational errors as the difference between core CPI inflation and by one-year inflation expectations from the Michigan Survey in the sample 1979-2006. We also add to the inflation process a normally distributed fundamental shock, $v_{t}^{\pi}$ matching the observed standard deviation over this period. ${ }^{12}$ In the top panel of Figure 2, the range for simulated inflation under the PCE policy rule is less than $2 \%$, whereas actual inflation ranges over 12\%. During the period of 1990-1999, the PCE policy rule simulates an inflation range of around $1 \%$ compared to the actual range of some $4 \%$. Finally in the bottom panel, we see a relatively close mapping between the PCE policy-induced inflation rate and actual inflation with ranges of a similar order of magnitude. This suggests that if the PCE policy rule had been adopted then the variance of actual inflation may have somewhat less than the observed one. But also that in the most recent period, the rules adoped by the Federal Reserve may have incoporated some elements of our suggested rule.

The problem for the policy-maker, who cannot know for certain whether there has been an expectational error, is to set rule-based policy so that even if there are expectational errors, the inflation process observes a process similar to that contained in Figure 2: where inflation in the presence of both fundamental and non-fundamental shocks can still locate a unique rational expectations equilibrium. Here we note that, while at the beginning of the sample the simulated inflation cannot track actual inflation, a closer

\footnotetext{
${ }^{10}$ Regularity refers to the Blanchard and Kahn (1980) condition for the existence of a rational expectations equilibria which in turn is related to the assumptions we make about predeterminacy or non-predeterminacy of relevant variables.

${ }^{11}$ In order to simulate the process for inflation we set $\phi=1$. We also set the initial value for the inflation to the actual level of US inflation.

${ }^{12}$ The mean and standard deviation of $\varpi_{t}$ and $v_{t}^{\pi}$ over this sample is $[1,0.36]$ and $[2.3$ $, 0.4]$, respectively.
} 

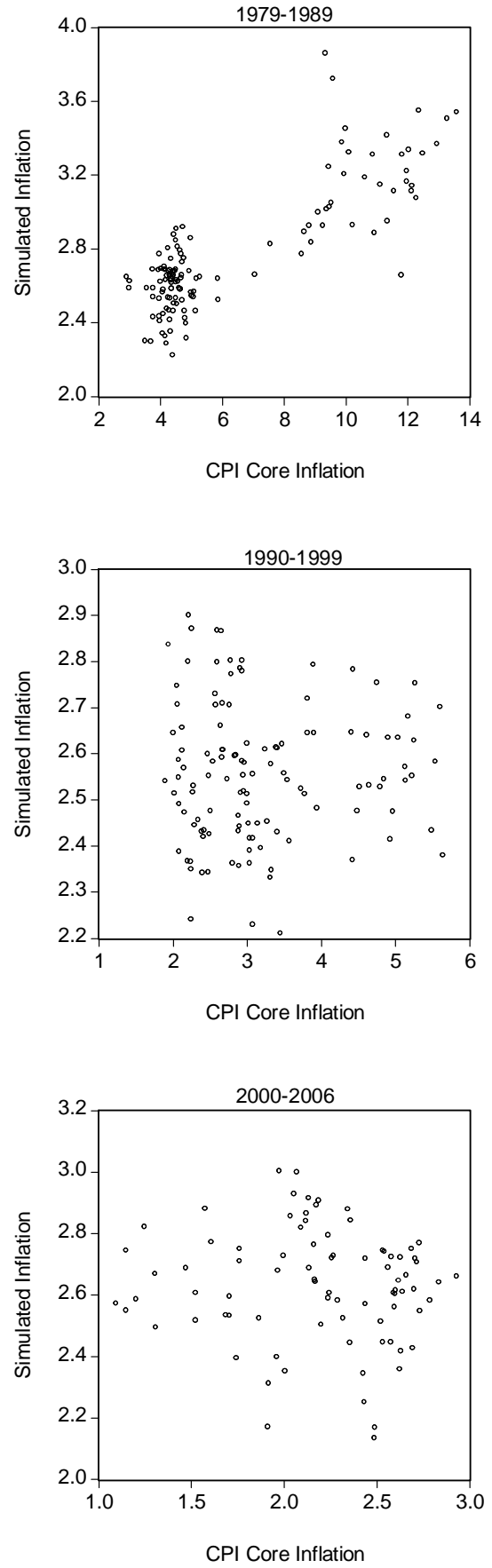

12

Figure 2: Inflation with Fundamental and Expectational Errors and a Stabilizing Policy Rule. 
Table 1: Standard Deviation of Actual and Simulated US Inflation

\begin{tabular}{cccc}
\hline \hline & Inflation & \multicolumn{2}{c}{ Simulated Solution } \\
\hline & & Indeterminate & Stabilizing \\
\hline $1979-1989$ & 3.04 & 7.29 & 0.32 \\
$1990-1999$ & 1.00 & 5.79 & 0.15 \\
$2000-2006$ & 0.45 & 3.44 & 0.18 \\
\hline \hline
\end{tabular}

correspondence can be found towards the end of the sample considered. ${ }^{13}$ Finally, Table 1 gives the standard deviation of CPI ex food and energy year-on-year inflation in the three-sub periods alongside the resuls of the simulation under an indeterminate rule (Figure 1) and a stabilizing rule (Figure 2). We show that the standard deviation of inflation in this decade has resembled that which would result from our stabilizing rule. In the following section we show how to derive an optimal rule for this system.

\section{An Expectations Based Timeless Targeting Criterion}

We now show that the rule identified in section 2.2.1 is the optimal response from an expectation based timeless perspective. We first define a loss function for the monetary authority. The central bank's problem at some point in time $(t=0)$ can be expressed as a minimization of the Lagrangian expression:

$$
L=\sum_{t=0}^{\infty} \beta^{t}\left\{\frac{1}{2}\left[\pi_{t}^{2}+\lambda y_{t}^{2}\right]+\varphi_{t}\left[\pi_{t}-\beta E_{t} \pi_{t+1}-\kappa y_{t}-v_{t}^{\pi}\right]\right\},
$$

where $\lambda$ is the relative weight between output and inflation in the loss function and $\varphi_{t}$ is the Lagrange multiplier. The authorities' minimization problem is subject to the constraint that the evolution for inflation represents a possible rational expectations equilibrium, i.e. that satisfies

\footnotetext{
${ }^{13}$ The results of this simulation of the same structural model for inflation where there are no expectational errors but still a stabilizing policy rule is in force, would be similar to that contained in Figure 2. Therefore, in line with Beyer and Farmer (2003), there is an observational equivalence between a world of expectational errors plus fundamentals and one of fundamental alone.
} 


$$
\pi_{t}=\beta E_{t} \pi_{t+1}+\kappa y_{t}+v_{t}^{\pi},
$$

for all periods $t \geqslant 1$. We assume that there is no welfare loss resulting from nominal interest rate variation as the policy rule is fully used to offset the inflation expectational errors and the other fundamental shocks (see also McCallum and Nelson, 2004; Woodford, 1999). Consequently, we omit the constraint on output as it does not bind.

Finally, output is given by:

$$
y_{t}=E_{t} y_{t+1}-\sigma\left(i_{t}-E_{t} \pi_{t+1}\right)+v_{t}^{y},
$$

where $\sigma>0$ and we assume that the economy is perturbed by a fundamental demand shock which satisfies $E_{t-1} v_{t}^{y}=0$. Hence the relevant constraint for the monetary authorities is that interest rates are set so that deviations of output and inflation from target - which are assumed to zero in both cases - are minimized given the constraint on inflation expectations as governed by equation (18).

The first order conditions of (17) w.r.t. $\pi_{t}$ and $y_{t}$ are:

$$
\begin{array}{ll}
\pi_{t}+\varphi_{t}-\varphi_{t-1}=0 & \text { for } t=1,2, \ldots \\
\lambda y_{t}-\kappa \varphi_{t}=0 & \text { for } t=1,2, . .
\end{array}
$$

The central bank ignores the start-up condition $\pi_{1}+\varphi_{1}=0$ and applies (20) and (21) in all periods. And so there will be no dynamic inconsistency as the relationship between $\pi_{2}$ and $y_{2}$ chosen in period 2 agrees with the relationship planned in period 1.

Combining (20) and (21), the evolution of inflation satisfies:

$$
\kappa \pi_{t}+\lambda y_{t}=\lambda y_{t-1} .
$$

According to (22) the optimal rule with commitment must be dynamically consistent in each time period and hence history dependent (Woodford, 2000). ${ }^{14}$ But we know from Section 2 that such a rule will not be sufficient to stabilize a forward-looking model with expectational errors. The second stage requires the expectational error to be expressed as a function

\footnotetext{
${ }^{14}$ The optimal targeting criterion, as also stressed by Woodford (2003a), suggests that with an optimal time consistent rule it is the rate of change rather than the absolute level (as in the discretionary case) that should determine acceptable deviations from the long-run inflation target.
} 
of fundamental shocks, which are in turn restricted to cancel expectational errors. The monetary authorities should therefore condition their policy action on the structural equations of the model characterizing fundamental shocks and endogenous variables (Evans and Honkapohja, 2006). ${ }^{15}$

In our case the targeting criterion will be expressed as an interest rate rule that is a function of the exogenous disturbances and of period $t$ and $t-1$ expectations of state variables. Solving the Phillips' curve for $y_{t-1}$ and substituting both $y_{t-1}$ and the structural equations for $\pi_{t}$ and $y_{t}$, as defined in (18) and (19), into the timeless criterion (22), we obtain the expectations based reaction function:

$$
\begin{aligned}
i_{t}= & \frac{1}{\sigma} E_{t} y_{t+1}+\left(1+\frac{\kappa \beta}{\sigma\left(\lambda+\kappa^{2}\right)}\right) E_{t} \pi_{t+1}+\frac{\lambda}{\kappa \sigma\left(\lambda+\kappa^{2}\right)}\left(\beta E_{t-1} \pi_{t}-\pi_{t-1}\right) \\
& +\frac{\kappa}{\sigma\left(\lambda+\kappa^{2}\right)} v_{t}^{\pi}+\frac{\lambda}{\sigma k\left(\lambda+\kappa^{2}\right)} v_{t-1}^{\pi}+\frac{1}{\sigma} v_{t}^{y} .
\end{aligned}
$$

This solution has arguments in both past, current and expected inflation as in proposition 3 . The interest rate targeting rule (23) acts twofold to rule out expectational errors: $(i)$ it introduces a backward inflation component which acts as a stationary control for the formation of future inflation expectations; (ii) it eradicates the expectational shocks by expressing them as a function of the fundamentals shocks, $v_{t}^{y}$ and $v_{t}^{\pi}$. So the interest rate today will respond to expected inflation, current inflation and past inflation. The anchor to past inflation is required to introduce a correction to previous errors in the forward-looking system and it has the effect of mitigating the inflationary spiral of pure forward-looking rules. ${ }^{16}$ So if the expectation at time $t-1$ of inflation at time $t, E_{t-1} \pi_{t}$, is greater than inflation at time $t-1$, i.e. agents expect inflation to rise, then the policy maker should increase the interest rate. Note also that the rule totally offsets the demand shock, $v_{t}^{y}$.

\footnotetext{
${ }^{15}$ Evans and Honkapohja (2003) show that a fundamental based policy rule which would be the optimal rule without commitment, when private agents have perfectly rational expectations, is unstable if in fact agents follow standard adaptive learning rules. To achieve a monetary policy which both is stable under learning and implements optimal discretionary policy the design of the rule must explicitly take into account of private sector expectations and the economic structure. However, the rule derived under learning is not unique.

${ }^{16}$ Rotemberg and Woodford (1999) also derive optimal generalized rules where explosive growing response of the funds rate to deviation of inflation from target are 'avoided only if subsequent deviations with the opposite sign eventually counteract the effects of an initial deviation' (p. 47).
} 
If the central bank commits itself to set the interest rate in accordance with this flexible reaction function, then the rational expectation equilibrium is necessarily determinate. We return to illustrate this result with reference to a number of policy experiments in section 5 .

\subsection{Stability Condition of the Timeless Criterion}

We now rewrite the timeless policy rule (23) in the simple case $\kappa=\sigma=1$ and $v_{t-1}^{\pi}=0$ and check whether this rule ensures determinacy:

$$
\begin{aligned}
i_{t}= & E_{t} y_{t+1}+\left(1+\frac{\beta}{(1+\lambda)}\right) E_{t} \pi_{t+1}+\frac{\lambda}{(1+\lambda)}\left(\beta E_{t-1} \pi_{t}-\pi_{t-1}\right) \\
& +\frac{1}{(1+\lambda)} v_{t}^{\pi}+v_{t}^{y} .
\end{aligned}
$$

The implied targeting rule suggests that to pin down a non-fundamental shock on inflation authorities should give a weight greater than one on forward-looking inflation. However this is a necessary but not sufficient condition as there should be also sufficient weight on past inflation, which should have a higher weight than the previous period's expectation of current inflation. This condition is automatically satisfied if $\beta<1$.

The model in its reduced form can be rewritten as:

$$
\begin{aligned}
{\left[\begin{array}{c}
\pi_{t} \\
E_{t} \pi_{t+1}
\end{array}\right]=} & {\left[\begin{array}{cc}
0 & 1 \\
-\beta^{-1} & 1+\frac{(1+\lambda)}{\lambda \beta}
\end{array}\right]\left[\begin{array}{c}
\pi_{t-1} \\
E_{t-1} \pi_{t}
\end{array}\right] } \\
& +\left[\begin{array}{cc}
0 & 1 \\
-\frac{1}{\beta} & \frac{1+\lambda}{\lambda \beta}
\end{array}\right]\left[\begin{array}{c}
v_{t}^{\pi} \\
\omega_{t}
\end{array}\right]
\end{aligned}
$$

Note that after substituting (24) in the inflation equation (18) both the expected output, $E_{t} y_{t+1}$, and the output shock, $v_{t}^{y}$, cancel out leaving a reduced form for inflation which is just a function of expected, current, past inflation and the inflation shock. We note that we have now one predetermined variable since the optimal rule is targeting both current, expected and past inflation, therefore introducing an inertial component in the reduced form equation for inflation.

We can easily show that the trace is $\operatorname{tr}\left(\mathbf{A}^{-1} \mathbf{B}\right)=1+\frac{1}{\beta}+\frac{1}{\lambda \beta}$ so it is positive and greater than two and $\operatorname{det}\left(\mathbf{A}^{-1} \mathbf{B}\right)=\frac{1}{\beta}$ so it is greater than one. This means that at least one of the roots lies outside the unit circle, therefore pinning down the non-predetermined variable (this can also be shown by 
calculating the roots of the characteristic equation for $\mathbf{A}^{-1} \mathbf{B}$ by hand). As a further proof of the existence of a saddle-point equilibrium we verify that the following conditions hold (see Woodford, 2003a, p. 671):

$$
\operatorname{det}\left(\mathbf{A}^{-1} \mathbf{B}\right)-\operatorname{tr}\left(\mathbf{A}^{-1} \mathbf{B}\right)=-1-\frac{1}{\lambda \beta}<-1
$$

and

$$
\operatorname{det}\left(\mathbf{A}^{-1} \mathbf{B}\right)+\operatorname{tr}\left(\mathbf{A}^{-1} \mathbf{B}\right)=1+\frac{2}{\beta}+\frac{1}{\lambda \beta}>-1 .
$$

In our case both conditions are fulfilled therefore implying that one of the roots is inside the unit circle.

Since the number of roots of $\mathbf{A}^{-1} \mathbf{B}$ which are less than one in absolute value are equal to the number of predetermined variables then the system is determinate. We will denote the characteristic roots of $\mathbf{A}^{-1} \mathbf{B}$ as $\theta^{s}$ and $\theta^{u}$ with $\left|\theta^{s}\right|<1$ and $\left|\theta^{u}\right|>1$. We can also express the non-fundamental shock $\omega_{t}$ as a function of the fundamental shock, $v_{t}^{\pi}$. This implies that even in the presence of expectational errors a timeless policy rule renders the equilibrium of the model determinate. As since the model (25) is regular and determinate we can derive an explicit solution for inflation in terms of the lag of inflation and the fundamental shock alone.

Proposition 4 With a timeless policy rule the rational expectations solution of the system is regular and determinate and can be expressed as a function of past inflation and fundamental shocks, which are in turn restricted to eradicate the expectational error:

$$
\pi_{t}=\theta^{s} \pi_{t-1}+\frac{\lambda}{(1+\lambda)}\left(1+\frac{\theta^{s}}{\theta^{u}-1}\right) v_{t}^{\pi} .
$$

Appendix $\mathrm{C}$ shows how to derive the result in the above proposition. The result follows as the reduced form (25) assumes the presence of a backward component of inflation in the optimal policy rule that acts to control our forward-looking system and allows us to express the non-fundamental shock as:

$$
\omega_{t}=\frac{\lambda}{(1+\lambda)}\left(1+\frac{\theta^{s}}{\theta^{u}-1}\right) v_{t}^{\pi},
$$

i.e. as a function of the fundamental shock pinning down any expectational error. ${ }^{17}$

\footnotetext{
${ }^{17}$ To derive this result we have used the conditions $\theta^{s}+\theta^{u}=\operatorname{tr}\left(A^{-1} B\right)$ and $\theta^{s} \theta^{u}=$
} 


\section{Numerical Analysis of the System}

We now turn to a numerical analysis of our artificial economy. We use Sims' method (2001), which has the advantage of exploiting the notion of the forecast errors introduced in (7). As we have shown in Section 3.1, under determinacy these forecast errors will be a function of the fundamental shocks. To assess how non-fundamental shocks influence the equilibrium dynamics we introduce (belief) shocks $\varepsilon_{t}^{\pi}$ and $\varepsilon_{t}^{y}$. As in Lubik and Schorfheide (2003) we assume that the belief shocks $\varepsilon_{t}^{\pi}$ and $\varepsilon_{t}^{y}$ lead to a revision of forecasts. Suppose that based on the forecasting error, there is a further revised by $\varepsilon_{t}^{\pi}$ and $\varepsilon_{t}^{y}$ to beliefs:

$$
\begin{aligned}
& \varepsilon_{t}^{\pi}=f\left(\omega_{t}^{\pi}\right), \\
& \varepsilon_{t}^{y}=f\left(\varepsilon_{t}^{y}\right),
\end{aligned}
$$

where $\omega_{t}^{\pi}$ and $\omega_{t}^{y}$ is the forecast error for inflation or output between $t-1$ and $t$.

The reduced form described by (18), (19) and (23), following Lubik and Schorfheide (2003), can be expressed in terms of the forecast errors (30) and (31) as:

$$
\begin{gathered}
E_{t-1} \pi_{t}=\beta E_{t} \pi_{t+1}+\kappa E_{t-1} y_{t}+\kappa\left(\omega_{t}^{y}+\varepsilon_{t}^{y}\right)-\left(\omega_{t}^{\pi}+\varepsilon_{t}^{\pi}\right)+v_{t}^{\pi} \\
E_{t-1} y_{t}=E_{t} y_{t+1}-\sigma i_{t}+\sigma E_{t} \pi_{t+1}-\left(\omega_{t}^{y}+\varepsilon_{t}^{y}\right)+v_{t}^{y}, \\
i_{t}=\phi_{1} E_{t} \pi_{t+1}+\phi_{2} E_{t} y_{t+1}+\phi_{3} E_{t-1} \pi_{t}-\phi_{4} \pi_{t-1} \\
+\phi_{2} v_{t}^{y}+\frac{\kappa^{2}}{\lambda} \phi_{4} v_{t}^{\pi}+\phi_{4} v_{t-1}^{\pi}
\end{gathered}
$$

where $\phi_{1}=\left(1+\frac{\beta \kappa}{\sigma\left(\lambda+\kappa^{2}\right)}\right), \phi_{2}=\frac{1}{\sigma}, \phi_{3}=\frac{\lambda \beta}{\sigma k\left(\lambda+\kappa^{2}\right)}, \phi_{4}=\frac{\lambda}{\sigma k\left(\lambda+\kappa^{2}\right)}$.

The model can be represented as a six dimensional system that includes the conditional expectations $E_{t} \pi_{t+1}$ and $E_{t} y_{t+1}$ as endogenous variables. As the inflation shock enters with a lag it has to be treated as an endogenous $\overline{\operatorname{det}\left(A^{-1} B\right) \text { which allow us to express }} A^{-1} B$ as:

$$
\left[\begin{array}{cc}
0 & 1 \\
-\theta^{s} \theta^{u} & \theta^{s}+\theta^{u}
\end{array}\right]
$$


variable in the system. Defining $\mathbf{X}_{t}=\left[\pi_{t}, y_{t}, i_{t}, E_{t} \pi_{t+1}, E_{t} y_{t+1}, v_{t}^{\pi}\right]$ the system can be rewritten as:

$$
\mathbf{A X}_{t}=\mathbf{B X}_{t-1}+\left[\begin{array}{ll}
\boldsymbol{\Psi} & \Pi
\end{array}\right]\left[\begin{array}{c}
\boldsymbol{\mu}_{t} \\
\varepsilon_{t}
\end{array}\right]+\Pi \boldsymbol{\omega}_{t}
$$

where the vector of exogenous shocks $\mathbf{e}_{t}=\left[\mu_{t}^{\pi}, \mu_{t}^{y}, \varepsilon_{t}^{\pi}, \varepsilon_{t}^{y}\right]^{\prime}=\left[\boldsymbol{\mu}_{t} \varepsilon_{t}\right]^{\prime}$ comprises the vector of fundamental shocks, $\boldsymbol{\mu}_{t}$, and by the vector of belief shocks, $\varepsilon_{t}$, which is serially uncorrelated. Belief shocks are thus treated as exogenous alongside the fundamental shocks $\boldsymbol{\mu}_{t} \cdot{ }^{18}$ Finally, the vector $\boldsymbol{\omega}_{t}=\left[\omega_{t}^{y}, \omega_{t}^{\pi}\right]$ identifies the endogenous expectational errors.

The matrices of this system can be expressed as:

$$
\begin{aligned}
\mathbf{A}= & {\left[\begin{array}{cccccc}
1 & 0 & 0 & 0 & 0 & 0 \\
0 & 1 & 0 & 0 & 0 & 0 \\
0 & 0 & -1 & \phi_{1} & \phi_{2} & \frac{\kappa^{2}}{\lambda} \phi_{4} \\
0 & 0 & 0 & \beta & 0 & 1 \\
0 & 0 & -\sigma & \sigma & 1 & 0 \\
0 & 0 & 0 & 0 & 0 & 1
\end{array}\right] } \\
\mathbf{B}= & {\left[\begin{array}{cccccc}
0 & 0 & 0 & 1 & 0 & 0 \\
0 & 0 & 0 & 0 & 1 & 0 \\
\phi_{4} & 0 & 0 & -\phi_{3} & 0 & -\phi_{4} \\
0 & 0 & 0 & 1 & -\kappa & 0 \\
0 & 0 & 0 & 0 & 1 & 0 \\
0 & 0 & 0 & 0 & 0 & 0
\end{array}\right] } \\
\boldsymbol{\Psi}= & {\left[\begin{array}{cc}
0 & 0 \\
0 & 0 \\
0 & -\phi_{2} \\
0 & 0 \\
0 & -1 \\
1 & 0
\end{array}\right], }
\end{aligned}
$$

The Jordan form of matrix $\mathbf{A}^{-1} \mathbf{B}$ (Sims, 2001) is $\mathbf{P}^{-1} \mathbf{\Theta P}$ where $\mathbf{P}$ and $\mathbf{P}^{-1}$ are the matrices of eigenvectors and $\boldsymbol{\Theta}$ is the matrix of eigenvalues. Multiplying the system by $\mathbf{P}$ and defining $\mathbf{Z}_{t}=\mathbf{P} \mathbf{X}_{t}$ we can rewrite the above expression as:

$$
\mathbf{Z}_{t+1}=\Theta \mathbf{Z}_{t}+\mathbf{P A}^{-1}\left[\begin{array}{ll}
\Psi & \Pi
\end{array}\right]\left[\begin{array}{c}
\boldsymbol{\mu}_{t} \\
\varepsilon_{t}
\end{array}\right]+\mathbf{P A}^{-1} \Pi \boldsymbol{\omega}_{t}
$$

\footnotetext{
${ }^{18}$ Note that as the output shock does not enter with any lag $v_{t}^{y}=\mu_{t}^{y}$. Note that we do not have a vector of constants as all variables are expressed as deviations from steady-state.
} 
The solution can be written in decoupled form as:

$$
\left[\begin{array}{l}
\mathbf{Z}_{t+1}^{s} \\
\mathbf{Z}_{t+1}^{u}
\end{array}\right]=\left[\begin{array}{ll}
\Theta^{s} & 0 \\
0 & \Theta^{u}
\end{array}\right]\left[\begin{array}{l}
\mathbf{Z}_{t+1}^{s} \\
\mathbf{Z}_{t+1}^{u}
\end{array}\right]+\left[\begin{array}{l}
\boldsymbol{\xi}_{t+1}^{s} \\
\boldsymbol{\xi}_{t+1}^{u}
\end{array}\right]
$$

where the superscript $s$ stands for stable and $u$ for unstable and $\boldsymbol{\xi}_{t+1}=$ $\mathbf{P A}^{-1}\left[\begin{array}{ll}\boldsymbol{\Psi} & \boldsymbol{\Pi}\end{array}\right]\left[\begin{array}{c}\boldsymbol{\mu}_{t} \\ \varepsilon_{t}\end{array}\right]+\mathbf{P A}^{-\mathbf{1}} \boldsymbol{\Pi} \boldsymbol{\omega}_{t}$.

The unstable block can be iterated forward to give the set of stability conditions for $\mathbf{Z}_{t}^{u}=-\sum_{j=0}^{\infty}\left(\Theta^{u}\right)^{-(j+1)} \boldsymbol{\xi}_{t+j}^{u} \cdot{ }^{19}$ In order to ensure stability of the forward-looking variables we impose the condition $\mathbf{Z}_{t}^{u}=0$ :

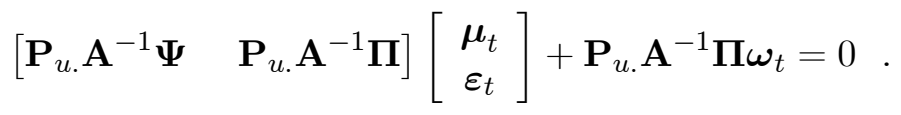

hence

$$
\boldsymbol{\omega}_{t}=\left[\begin{array}{ll}
\Psi & \boldsymbol{\Pi}
\end{array}\right]\left[\begin{array}{l}
\boldsymbol{\mu}_{t} \\
\varepsilon_{t}
\end{array}\right]
$$

To ensure stability the expectational errors, $\boldsymbol{\omega}_{t}$, are expressed as a function of the fundamental shock, $\boldsymbol{\mu}_{t}$, and of the non-fundamental shocks, $\varepsilon_{t}$. Hence even with belief shocks we can generate the full set of stable solutions to the system, as long as equation (39) is satisfied. This result is analogous to (29), which was derived for the stylized reduced form model (25), where the stable solution for inflation expresses the non-fundamental expectational error as a function of the fundamental shock. If the condition (39) is fulfilled the system is determinate i.e. the policy has successfully eliminated any possible influence of expectational errors in the system. ${ }^{20}$

\footnotetext{
${ }^{19}$ Note that

$$
\mathbf{Z}_{t}^{u}=\left(\boldsymbol{\Theta}^{u}\right)^{-1} \mathbf{Z}_{t+1}^{u}-\left(\boldsymbol{\Theta}^{u}\right)^{-1} \boldsymbol{\xi}_{t}^{u}=\left(\boldsymbol{\Theta}^{u}\right)^{-2} \mathbf{Z}_{t+2}^{u}-\left(\boldsymbol{\Theta}^{u}\right)^{-2} \boldsymbol{\xi}_{t+1}^{u}-\left(\boldsymbol{\Theta}^{u}\right)^{-1} \boldsymbol{\xi}_{t}^{u}
$$
}

which gives the result in the text.

${ }^{20}$ Determinacy problems may arise if there are insufficient exogenous shocks $\mu_{t}$ and $\varepsilon_{t}$ to offset the endogenous non-fundamental shocks in $\omega_{t}$. In order for the solution to be determinate, (39) has to pin down not only $P^{u} \Pi \omega$ but also all the other error terms in the system that are affected by the expectational sunspot error term $\omega$. That is from the knowledge of $P^{u} \Pi \omega$ we must be able to determine $P^{s} \Pi \omega$ where $P^{s}$ includes the rows of $P^{-1}$ not included in $P^{u}$ (Sims, 2001). In addition if $P^{u}$ has more rows than columns this problem is equivalent to the usual notion that there are regularity problems as the number of unstable roots exceeds the number of jump variables. 


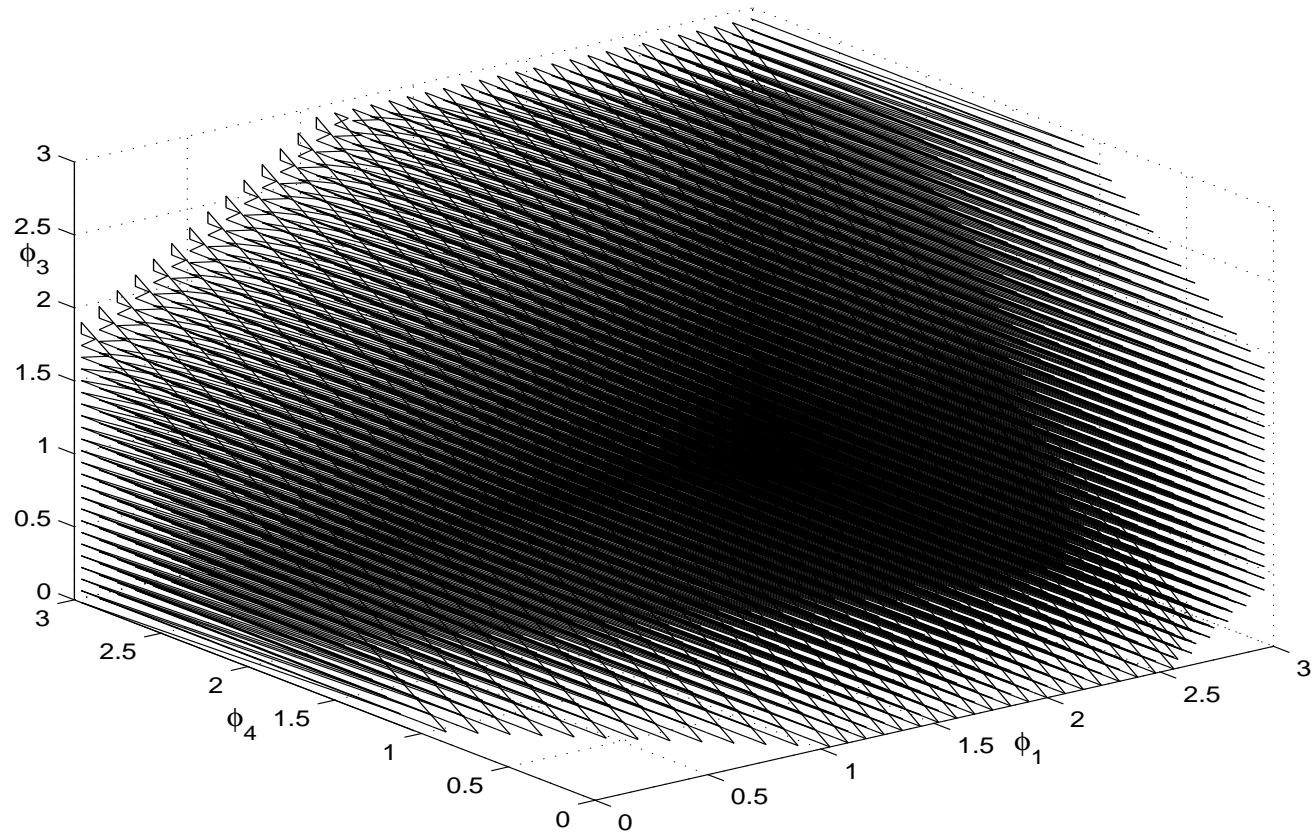

Figure 3: Local Determinacy of System Solution

\subsection{Local Determinacy of the System}

To analyze the local determinacy of the system and its dynamic properties we start by assigning some standard benchmark values to $\sigma, \beta$ and $\kappa$. Following Rotemberg and Woodford (1998) and most of standard literature we set the (quarterly) discount factor $\beta$ to 0.99 , implying an annual rate of $4 \%$. We also set the coefficient of relative risk aversion, $\sigma$, to 1.0 and the output elasticity of inflation, $\kappa$, equal to 0.3 which is chosen by Woodford (1999). We also set the relative weight of output with respect to inflation in the loss function to be equal to 0.1 .

Figure 3 indicates whether the solution to the system defined by (32), (33) and (34) is determinate. We fix a grid of admissible values for each of the interest rate rule coefficients on expected, current and backward inflation $\phi_{1}, \phi_{3}$ and $\phi_{4}$ which are defined in (34) and examine whether the solution is determinate. The darker regions of Figure 3 correspond to the stable zones of the system. In forward-looking systems characterized by forecast errors caused by non-fundamental shocks a coefficient greater than unity 
on expected inflation $\left(\phi_{1}>1\right)$ is not sufficient to guarantee stability. As proposition 3 states we need all the components of inflation (backward, current and expected) to enter the feedback rule with the coefficients $\phi_{1}$ and $\phi_{4}$ greater than unity. The darkest region of Figure 4 shows the solution is always determinate where $\phi_{1}, \phi_{3}$ and $\phi_{4}$ are greater than one.

\subsection{Policy Experiments}

We now turn to some policy experiments on system defined by (32), (33) and (34) by comparing the impulse responses for inflation, output and real interest rates to the fundamental shocks and to the non-fundamental shock on inflation. ${ }^{21}$ Figure 4 compares the responses of $\pi_{t}, y_{t}$ and $i_{t}-\pi_{t}$ to the set of shocks $\left[\mu_{t}^{\pi}, \mu_{t}^{y}, \varepsilon_{t}^{\pi}\right]$ when we implement the Past-Current-Expected (PCE) policy rule and when we implement a Past-Current (PC) rule. From our simulations, it is clear that failure or delay to adopt PCE rule will result in more inflation and output persistence.

A cost-push shock, $\mu_{t}^{\pi}$, that hits aggregate supply, causes a temporary increase in inflation. With a PCE rule nominal interest rates increase sharply in response to the higher levels of current and expected inflation. Because of the higher real interest rates output decreases. In the subsequent periods real rates will then gradually revert to their long-run level, which in turn will boost output back to equilibrium. The main difference between both the $\mathrm{PCE}$ and the $\mathrm{PC}$ rule is that when there are forward-looking components, inflation dynamics are less persistent and revert quicker to its long-run equilibrium. In general the PCE rule performs better than the PC rule, as the fluctuations in both inflation and output are lower. Conversely the purely backward-looking PC rule is not capable of stabilizing inflation.

In presence of a demand shock, $\mu_{t}^{y}$, the real interest rate picks up immediately after the shock to avoid inflationary spirals. Note that in this case the initial shock is fully compensated by the increase in interest rates at time zero. So neither output nor inflation will be subject to variations -there are just infinitesimal fluctuations around zero. That the demand shock affects only interest rate can be seen from the simpler feedback rule

\footnotetext{
${ }^{21}$ Given the solution $X_{t}=G_{1} X_{t-1}+W_{t} e_{t}$ we can write the VAR in standard $\operatorname{MA}(\infty)$ form as:

$$
\mathbf{X}_{t}=\sum_{i=0}^{\infty} \mathbf{G}_{1}^{i} \mathbf{W}_{t-i} \mathbf{e}_{t-i}=\sum_{i=0}^{\infty} \mathbf{C}_{t-i} \mathbf{e}_{t-i}
$$

The responses of $X_{t}$ are determined by the rows of $G_{1}^{i}$ and $W_{t-i}$. These are the responses of $X$ to standard shocks in $e_{t}$ i.e. $X_{t}=C_{t} e_{t}+C_{t-1} e_{t-1}+C_{t-2} e_{t-2} \ldots$ where the matrix $C_{k}$ has the interpretation $\frac{\partial \mathbf{X}_{t}}{\partial \mathbf{e}_{t-k}}=C_{t-k}$ which will be used in our impulse response analysis.
} 
(24), where the interest rate responds one to one to the output shock, therefore offsetting its effects in all the other equations. As we assume that full stabilization on the output shock occurs with all the rules in the same manner, the real interest rate will be identical in all the two scenarios.

The final column of charts in Figure 4, assumes a non-fundamental shock in inflation, $\varepsilon_{t}^{\pi}$. In this case real rates have to increase in order to offset the inflation non-fundamental shock. However, when adopting a PCE rule there will be no possibility for the inflation expectational error to settle in the economy as by definition the system is determinate, so a PCE rule will rule the non-fundamental errors out. There are clear differences in the responses to a PCE as compared to the PC rule. A PCE rule will respond initially more to the inflation expectational error (real rates are initially higher with the PCE than with the PC rule). This response causes a fall in inflation which in turn, given the history dependent pattern, will cause a reduction in nominal rates (and real rates) in the following periods. In turn the PCE rule will successfully stabilize inflation and will reduce volatility of both output and inflation.

Finally, Figure 5 compares the responses of $\pi_{t}, y_{t}$ and $i_{t}-\pi_{t}$ to the set of shocks $\left[\mu_{t}^{\pi}, \mu_{t}^{y}, \varepsilon_{t}^{\pi}\right]$ by varying the relative weight on output, $\lambda$, in the loss function. For low levels of $\lambda$, i.e. when the weight attached to the inflation objective is higher, an inflation shock causes a sharper increase in the real interest rate and therefore a more pronounced reduction in output. Also inflation and output are less persistent and revert quicker to their long-run equilibrium. Similarly, when an expectational error hits the economy, there will be a faster adjustment of inflation towards equilibrium when the value of lambda is lower.

\section{Conclusions}

A pragmatic monetary policy maker may wish to use each of the history for, current and expected inflation as information variables when following a monetary rule. But such an approach cannot be explained alone by the need to stabilize fundamental shocks (see Clarida et al, 2000). But we show that it can, however, be explained well when there is the additional possibility of non-fundamental shocks, or expectational errors. We suggest that responding to both leads and lags of inflation may therefore represent a sensible stabilization strategy in the face of the possibility of expectational errors.

As suggested by Orphanides and Williams (2005) and Evans and 

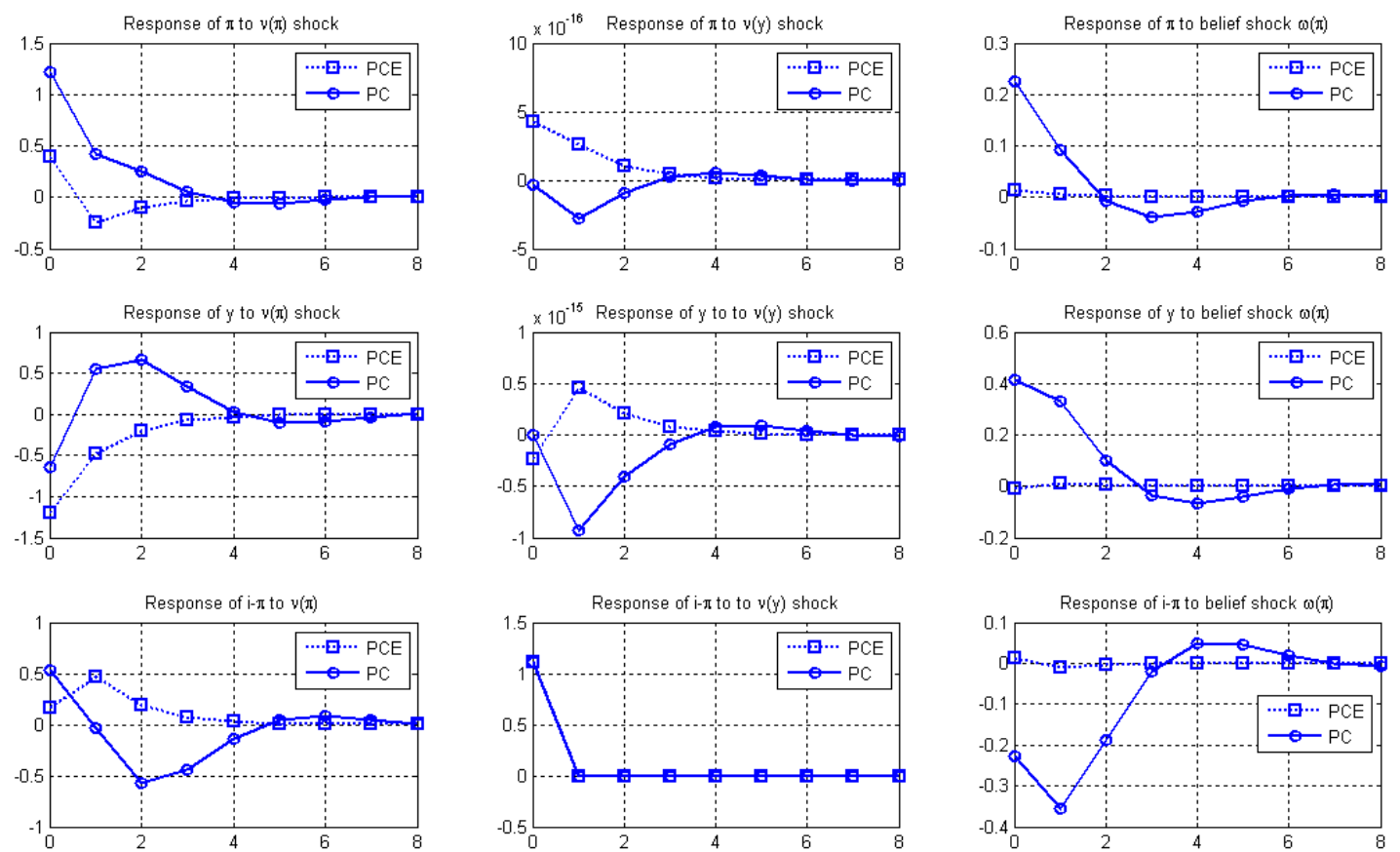

Figure 4: Responses of $\pi_{t}, y_{t}$ and $i_{t}-\pi_{t}$ to the fundamental and nonfundamental shocks $\left[\mu_{t}^{\pi}, \mu_{t}^{y}, \varepsilon_{t}^{\pi}\right]$ to different policy rules. 

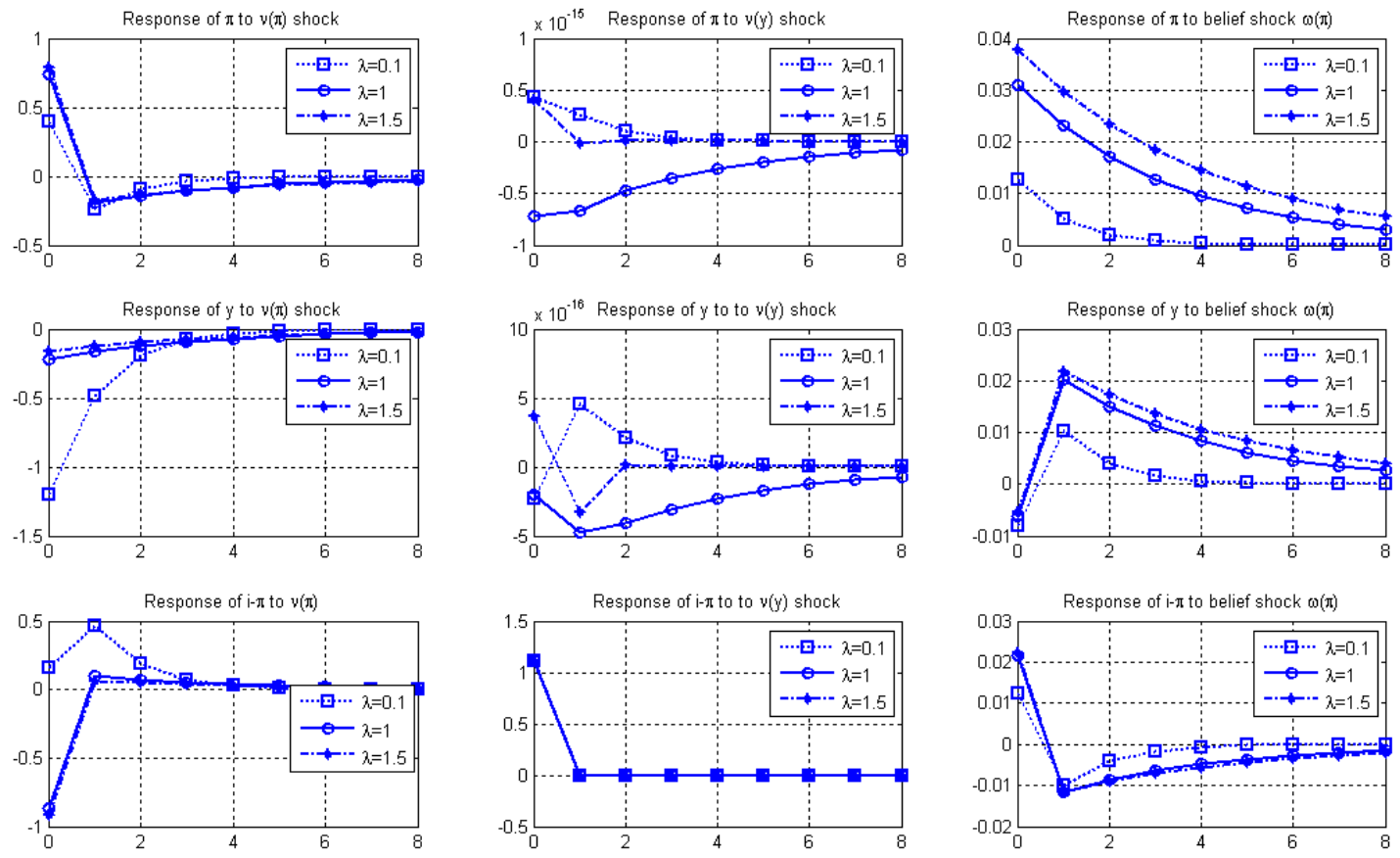

Figure 5: Responses of $\pi_{t}, y_{t}$ and $i_{t}-\pi_{t}$ to the fundamental and nonfundamental shocks $\left[\mu_{t}^{\pi}, \mu_{t}^{y}, \varepsilon_{t}^{\pi}\right]$ to different values of the output weight $\lambda$. 
Honkapohja (2003), if the process for inflation is learnable, inflation forecast errors may be ruled out by a simple forecast-based rule. However, if we also consider the possibility that expectational errors in inflation are systemic then we prove the intuition of Calmstrom and Fuerst $(2000,2004)$ that a rule which responds to past inflation will produce stability whereas one that is solely forward-looking cannot. It has not escaped our attention that a formal inflation target may be interpreted to be such a form of commitment to past inflation deviations. ${ }^{22}$

In this paper we derive a general class of policy rules able to deal with the determinacy of the model economy when expectational errors are systemic. The policy implication of the optimal rule derived - the PCE rule - is that the central bank should coordinate its stabilization effort by responding to each of lagged, current and expected inflation. That is commit to reponding to previous errors and as well as current and expected errors in inflation. We also show that the PCE rule derived is analogous to the timeless policy rule of Woodford (2003b) and to the expectational rule of Evans and Honkapohja (2006). Hence an optimal policy rule will stabilize a forward-looking system that is prone to expectational errors if it is inertial (in the sense that the rule is constrained by past errors) and if this self-same rule is 'learnable' i.e. meets supplementary conditions for stability and uniqueness.

We illustrate our arguments with reference to the performance of US inflation since the late 1970s and suggest that it might be possible to explain some of the reduction in the levels of both inflation and its persistence during the so-called 'Great Moderation' period as resulting from the implementation of some form of PCE rule for monetary policy. It would appear from our work that if expectational errors cannot be ruled out then co-ordinating stabilization policy across time will act to contain many of the deleterious effects.

\section{References}

[1] Batini, N. and J. Pearlman (2002), Too Much Too Soon: Instability and Indeterminacy with Forward-Looking Rules, External MPC Unit Bank of England Discussion Paper No. 8.

\footnotetext{
${ }^{22}$ For example, the Governor of the Bank of England wrote a letter to the Chancellor of the Exchequer on 17th April 2007 because CPI inflation in the year to March 2007 exceeded the Government's inflation target by $1 \%$. In some sense, the Governor has a commitment to correct this past deviation.
} 
[2] Benhabib, J., Schmitt-Grohe, S. and Uribe, M. (2001), Monetary Policy and Multiple Equilibria, American Economic Review, 91(1), 167-86.

[3] Benhabib, J., Schmitt-Grohe S. and M. Uribe (2002), Avoiding Liquidity Traps, Journal of Political Economy, vol. 110(3), 535-563.

[4] Benhabib, J., Schmitt-Grohe, S. and Uribe, M. (2004), Chaotic Interest Rate Rules: Expanded Version, NBER Working Paper 10272.

[5] Bernanke, B. (2003), A Perspective on Inflation Targeting, Speech to National Association of Business Economists, March 25.

[6] Bernanke, B. and Woodford, M. (1997), Inflation Forecasts and Monetary Policy, Journal of Money Credit and Banking, vol. 24, 653684.

[7] Beyer, A. and R. E. A. Farmer (2003), On the Indeterminacy of Determinacy and Indeterminacy, European Central Bank working paper No. 277.

[8] Blanchard, O. and K. C. Kahn, The Solution of Linear Difference Models under Rational Expectations, Econometrica, 48(5), July 1980, 1305-11.

[9] Bullard, J. and Mitra K. (2002), Learning about Monetary Policy Rules, Journal of Monetary Economics, 49, 1105-1129.

[10] Carlstrom, C. T. and Fuerst, T. S. (2000), Forward-Looking versus Backward-looking Taylor rules, Federal Reserve Bank of Cleveland Working Paper.

[11] Carlstrom, C. T. and Fuerst, T. S. (2004), Learning and the Central Bank, Journal of Monetary Economics, 51, 327-338.

[12] Chadha, J. S. (2006), Policy Rules Under Monetary and Fiscal Theories of the Price Level, forthcoming Ekonomia.

[13] Chari,V. V., Christiano, L. J., and Eichenbaum, M. (1998), Expectation Traps and Discretion, Journal of Economic Theory, 81(2), 462-92.

[14] Clarida, R., Gali, J. and Gertler, M. (2000), Monetary Policy Rules and Macroeconomic Stability: Evidence and Some Theory, Quarterly Journal of Economics, 115(1), 147-80. 
[15] Evans, G. W. and Honkapohja, S. (2003), Expectations and the Stability Problem for Optimal Monetary Policy, Review of Economic Studies, 70, 807-824

[16] Evans, G. W. and Honkapohja, S. (2006), Monetary Policy, Expectations amd Commitment, The Scandinavian Journal of Economics, 2006, Vol. 108, 15-38.

[17] Farmer R. E. A., Waggoner, D. F. and Zha T. (2006), Indeterminacy in a Forward-Looking Regime Switching Model, NBER Working Paper No. W12540.

[18] Honkapohja, S. and Mitra, K. (2004), Are Non-Fundamental Equilibria Learnable in Models of Monetary Policy?, Journal of Monetary Economics, 51, 1743-1770.

[19] Ireland, P. (2003), Irrational Expectations and Econometric Practice: Dicussion of Orphanides and Williams: Inflation Scares and ForecastBased Monetary Policy, Federal Reserve Bank of Atlanta, WP 2003-22.

[20] King, M. (2005). Monetary Policy: Practice Ahead of Theory, Mais Lecture 2005, Cass Business School, City University, London.

[21] Lubik, T. A. and F. Schorfheide (2003), Computing Sunspot Equilibria in Linear Rational Expectations Models, Journal of Economic Dynamics and Control, 28, 273-285.

[22] Mankiw, N. G., Reis, R. and Wolfers J. (2003), Disagreement about Inflation Expectations. NBER Working Paper No. 9796.

[23] McCallum, B. T. and Nelson, E., (2004), Timeless Perspective vs. Discretionary Monetary Policy in Forward-Looking Models, Federal Reserve Bank of St. Louis Review, March/April 2004, 86(2), 43-56.

[24] Orphanides, A., and J. Williams (2005), Inflation Scares and ForecastBased Monetary Policy, Review of Economic Dynamics 8(2), 498-527.

[25] Rotemberg, J.J. and M. Woodford (1998), An Optimization-Based Econometric Framework for the Evaluation of Monetary Policy: Expanded Version, NBER Technical Working Paper 233.

[26] Rotemberg, J.J. and M. Woodford (1999), Interest-Rate Rules in an Estimated Sticky-Price Model, in J.B. Taylor, ed., Monetary Policy Rules, University of Chicago Press. 
[27] Schmitt-Grohe, S. and Uribe, M., (2000), Price Level Determinacy and Monetary Policy under a Balanced-budget Requirement, Journal of Monetary Economics, 45, 211-246.

[28] Sims, Christopher, A. (2001), Solving Linear Rational Expectations Models, Computational Economics, 20, 1-20.

[29] Trichet, J. (2005), Monetary Policy and Credible Alertness, Panel Discussion on "Monetary Policy Strategies: A Central Bank Panel, at the Symposium sponsored by the Federal Reserve Bank of Kansas City, Jackson Hole, Wyoming.

[30] Woodford, M. (1999), Commentary: How Should Monetary Policy Be Conducted in an Era of Price Stability?, in New Challenges for Monetary Policy: A Symposium Sponsored by the Federal Reserve Bank of Kansas City. Federal Reserve Bank of Kansas City, 277-316.

[31] Woodford, M. (2000), Pitfalls of Forward-Looking Monetary Policy, American Economic Review, 90(2), 100-104.

[32] Woodford, M. (2003a), Interest and Prices, Princeton University Press.

[33] Woodford, M. (2003b), Optimal Interest-Rate Smoothing, Review of Economic Studies, 70, 861-886.

[34] Woodford, M. (2005), Central-Bank Communication and Policy Effectiveness, the Woodford, Federal Reserve of Kansas City Conference "The Greenspan Era: Lessons for the Future", Jackson Hole, Wyoming. 


\section{A Some Simple Rules for Establishing Stability in $2 \times 2$ Matrix for a Difference Equation}

Let us define the polynomial function $p(\lambda)$

$$
p(\lambda)=\lambda^{2}-\lambda \operatorname{tr}\left(\mathbf{A}^{-1} \mathbf{B}\right)+\operatorname{det}\left(\mathbf{A}^{-1} \mathbf{B}\right)=0,
$$

where $\lambda$ will be a root of the equation when the polynomial equals zero. We therefore draw this polynomial in $\operatorname{tr}\left(\mathbf{A}^{-1} \mathbf{B}\right)=\operatorname{tr}(\bullet)$, $\operatorname{det}\left(\mathbf{A}^{-1} \mathbf{B}\right)=\operatorname{det}(\bullet)$ space for $\lambda$ as a root:

$$
\operatorname{det}(\bullet)=-\lambda^{2}+\lambda \operatorname{tr}(\bullet) .
$$

So for $\lambda=1$, this line be positive and for $\lambda=-1$ the line will be negative. The trace and determinant of a given $2 \times 2$ matrix will then determine how many eigenvalues will lie inside or outside the unit circle.

\section{A.1 Case 1 - saddle point: $\lambda_{1}<|1|$ and $\lambda_{2}>|1|$.}

No restrictions of either trace or determinant, per se.

For a positive trace:

$$
\begin{gathered}
\operatorname{det}(\bullet)<-1+\operatorname{tr}(\bullet) \\
\operatorname{det}(\bullet)>-1-\operatorname{tr}(\bullet) .
\end{gathered}
$$

As in (Woodford, 2003a) we observe that $\operatorname{tr}(\bullet)=\lambda_{1}+\lambda_{2}$ and $\operatorname{det}(\bullet)=$ $\lambda_{1} \lambda_{2}$. Conditions (A.3) and (A.4) imply respectively that $\left(\lambda_{1}-1\right)\left(\lambda_{2}-1\right)<0$ and $\left(\lambda_{1}+1\right)\left(\lambda_{2}+1\right)>0$. Hence the two roots are on the same side of 1 but one is greater than 1 and the other is less than 1 .

For a negative trace:

$$
\begin{aligned}
& \operatorname{det}(\bullet)>-1+\operatorname{tr}(\bullet) \\
& \operatorname{det}(\bullet)<-1-\operatorname{tr}(\bullet) .
\end{aligned}
$$

This implies that $\left(\lambda_{1}-1\right)\left(\lambda_{2}-1\right)>0$ and $\left(\lambda_{1}+1\right)\left(\lambda_{2}+1\right)<0$. Hence the two roots are on the same side of -1 but one is less than -1 and the other is greater than -1 . 


\section{B Policy Rules and Expectational Errors}

\section{B.1 Current inflation}

Let us now consider the forward-looking inflation equation $\pi_{t}=\beta E_{t} \pi_{t+1}+$ $k y_{t}$ but add a demand equation, $y_{t}=-\left(i_{t}-E_{t} \pi_{t+1}\right)$, and a policy rule targeting current inflation, $i_{t}=\phi \pi_{t}$. Setting $k=1$ the inflation equation can be rewritten as:

$$
\pi_{t}=(1+\beta) E_{t} \pi_{t+1}-\phi \pi_{t}
$$

Let us keep the same non-fundamental shock driving expectations. In reduced form this system is now:

$$
\begin{aligned}
{\left[\begin{array}{c}
\pi_{t} \\
E_{t} \pi_{t+1}
\end{array}\right]=} & {\left[\begin{array}{cc}
0 & 1 \\
0 & (1+\beta)^{-1}(1+\phi)
\end{array}\right]\left[\begin{array}{c}
\pi_{t-1} \\
E_{t-1} \pi_{t}
\end{array}\right]+} \\
& {\left[\begin{array}{c}
1 \\
(1+\beta)^{-1}(1+\phi)
\end{array}\right] \omega_{t} . }
\end{aligned}
$$

The system is regular ${ }^{23}$ when both (A.3) and (A.4) hold. This is true if $\phi>\beta$. However, there are no fundamental shocks in terms of which one may solve for the expectational errors. So the system in not determinate.

\section{B.1.1 Lagged Inflation}

Let us now consider a policy rule targeting past inflation. The reduced form system can be expressed as:

$$
\begin{aligned}
{\left[\begin{array}{c}
\pi_{t} \\
E_{t} \pi_{t+1}
\end{array}\right]=} & {\left[\begin{array}{cc}
0 & 1 \\
-\phi(1+\beta)^{-1} & (1+\beta)^{-1}
\end{array}\right]\left[\begin{array}{c}
\pi_{t-1} \\
E_{t-1} \pi_{t}
\end{array}\right] } \\
& +\left[\begin{array}{c}
1 \\
(1+\beta)^{-1}
\end{array}\right] \omega_{t} .
\end{aligned}
$$

If the equilibrium is unique there must be one unstable root that allows to pin down the expectational error. Given that $\operatorname{det}\left(\mathbf{A}^{-1} \mathbf{B}\right)=\phi(1+\beta)^{-1}>0$ it must be that the two eigenvalues have the same sign. But as $\operatorname{tr}\left(\mathbf{A}^{-1} \mathbf{B}\right)=(1+$ $\beta)^{-1}<1$ this implies that they are both less than 1 , whereas regularity requires at least one of the two roots to lie outside the unit circle. So the system is not either regular or determinate.

\footnotetext{
${ }^{23}$ In order to establish whether the system has a rational expectations equilibrium we must establish whether our variables are predetermined or non-predetermined. We can see that clearly $\pi_{t}$ is non-predetermined as it depends on how future expectations unfold. Whereas $\pi_{t}^{e}=E_{t-1} \pi_{t}$ is a predetermined as $E_{t-1} \pi_{t}^{e}=E_{t-1} E_{t-1} \pi_{t}=\pi_{t}^{e}$ (see also Sims, 2001).
} 


\section{B.1.2 Expected inflation and current inflation}

The policy rule is targeting both current and expected inflation in equal measure, $\phi$. The reduced form system is:

$$
\left[\begin{array}{c}
\pi_{t} \\
E_{t} \pi_{t+1}
\end{array}\right]=\left[\begin{array}{cc}
0 & 1 \\
0 & \frac{(1+\phi)}{(1+\beta-\phi)}
\end{array}\right]\left[\begin{array}{c}
\pi_{t-1} \\
E_{t-1} \pi_{t}
\end{array}\right]+\left[\begin{array}{c}
1 \\
\frac{(1+\phi)}{(1+\beta-\phi)}
\end{array}\right] \omega_{t} .
$$

The system is regular when both (A.3) and (A.4) hold. This is true if $\phi>\beta / 2$. However there are no fundamental shocks in terms of which one may solve for the expectational errors. So the system is not determinate.

\section{B.1.3 Backward inflation and current inflation}

The policy rule is targeting both current and backward inflation in equal measure, $\phi$. The reduced form system is:

$$
\left[\begin{array}{c}
\pi_{t} \\
E_{t} \pi_{t+1}
\end{array}\right]=\left[\begin{array}{cc}
0 & 1 \\
-\frac{\phi}{(1+\beta)} & \frac{1+\phi}{(1+\beta)}
\end{array}\right]\left[\begin{array}{c}
\pi_{t-1} \\
E_{t-1} \pi_{t}
\end{array}\right]+\left[\begin{array}{c}
1 \\
\frac{1+\phi}{(1+\beta)}
\end{array}\right] \omega_{t}
$$

This does not help either. The model reduces to a linear stochastic rational expectation model, with a predetermined variable. Regularity in this setting would require at least one of the two roots to lie outside the unit circle. Given the positive trace we can easily verify that the condition (A.3) $\operatorname{det}(\bullet)<-1+\operatorname{tr}(\bullet)$ is not satisfied. So the system is not either regular or determinate.

\section{Solution for Inflation}

In the simple case $\kappa=\sigma=1$, by replacing the interest rate rule (24) and the demand equation (19) in (18) we derive the reduced form equation for inflation. By combining the latter with the non-fundamental shock (7):

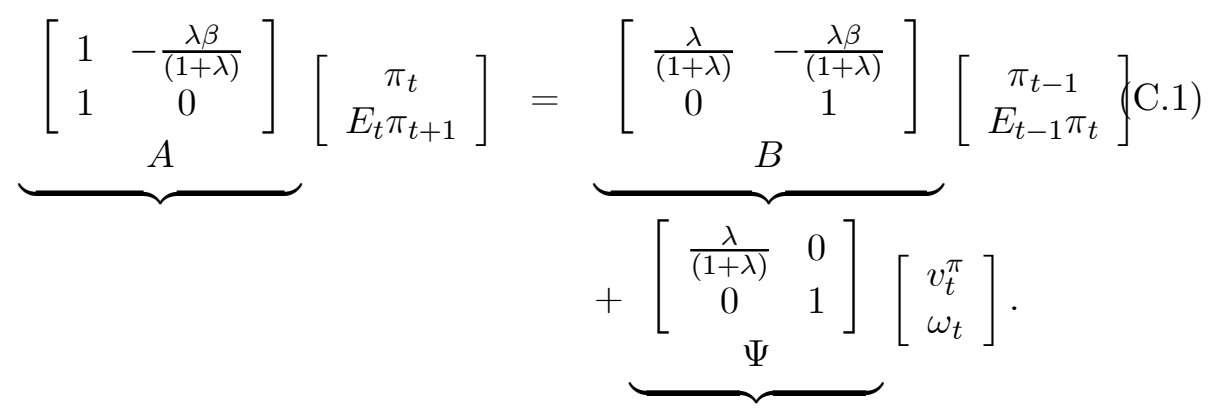


Multiplying by $A^{-1}$ :

$$
\left[\begin{array}{c}
\pi_{t} \\
E_{t} \pi_{t+1}
\end{array}\right]=A^{-1} B\left[\begin{array}{c}
\pi_{t-1} \\
E_{t-1} \pi_{t}
\end{array}\right]+A^{-1}\left[\begin{array}{cc}
\frac{\lambda}{(1+\lambda)} & 0 \\
0 & 1
\end{array}\right]\left[\begin{array}{c}
v_{t}^{\pi} \\
\omega_{t}
\end{array}\right]
$$

where $A^{-1}=\left[\begin{array}{cc}0 & 1 \\ -\frac{(1+\lambda)}{\lambda \beta} & \frac{1+\lambda}{\lambda \beta}\end{array}\right]$ and $A^{-1} B=\left[\begin{array}{cc}0 & 1 \\ -\beta^{-1} & 1+\frac{(1+\lambda)}{\lambda \beta}\end{array}\right]$.

The eigenvalues of $A^{-1} B$ are related to the parameters by the equations:

$$
\begin{aligned}
\theta^{s}+\theta^{u} & =1+\frac{1+\lambda}{\lambda \beta} \\
\theta^{s} \theta^{u} & =\beta^{-1} .
\end{aligned}
$$

So we can rewrite the above expression as:

$$
A^{-1} B=\left[\begin{array}{cc}
0 & 1 \\
-\theta^{s} \theta^{u} & \theta^{s}+\theta^{u}
\end{array}\right] .
$$

We have shown in the text that one of the roots lies outside the unit circle and another inside. Therefore we assume that $\theta^{u}>1$ and $\theta^{s}<1$.

The two eigenvectors of $A^{-1} B$ are equal to:

$$
\begin{aligned}
& {\left[\begin{array}{cc}
0 & 1 \\
-\theta^{s} \theta^{u} & \theta^{s}+\theta^{u}
\end{array}\right]\left[\begin{array}{l}
1 \\
v_{1}
\end{array}\right]=\theta^{s}\left[\begin{array}{l}
1 \\
v_{1}
\end{array}\right] \Longrightarrow v_{1}=\theta^{s}} \\
& {\left[\begin{array}{cc}
0 & 1 \\
-\theta^{s} \theta^{u} & \theta^{s}+\theta^{u}
\end{array}\right]\left[\begin{array}{l}
1 \\
v_{2}
\end{array}\right]=\theta^{u}\left[\begin{array}{l}
1 \\
v_{2}
\end{array}\right] \Longrightarrow v_{2}=\theta^{u}}
\end{aligned}
$$

The matrix $A^{-1} B$ can be decomposed as $Q \Theta Q^{-1}$ where $Q$ is the matrix of eigenvectors and $\Theta$ is a diagonal matrix which contains the eigenvalues of $A^{-1} B$ :

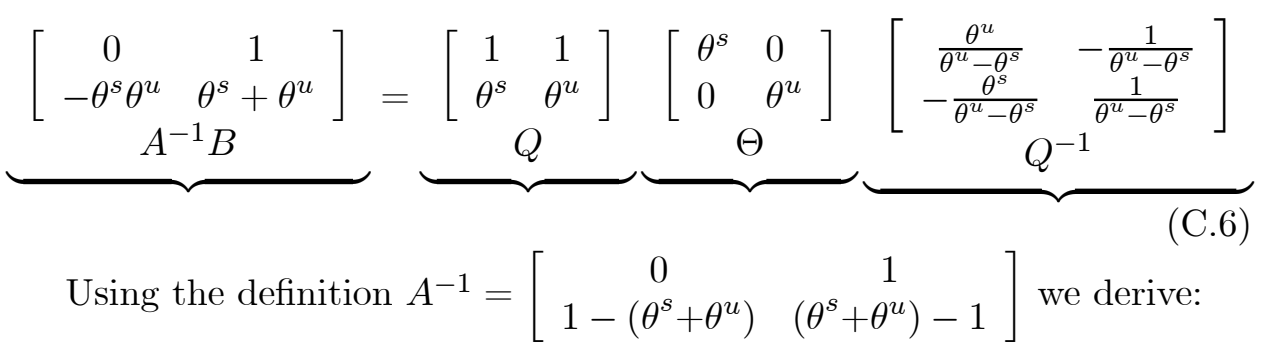




$$
Q^{-1} A^{-1}=\left[\begin{array}{cc}
\frac{\left(\theta^{s}+\theta^{u}\right)-1}{\theta^{u}-\theta^{s}} & -\frac{\theta^{s}-1}{\theta^{u}-\theta^{s}} \\
-\frac{\left(\theta^{s}+\theta^{u}\right)-1}{\theta^{u}-\theta^{s}} & \frac{\theta^{u}-1}{\theta^{u}-\theta^{s}}
\end{array}\right]
$$

Premultiply (C.2) by $Q^{-1}$ :

$$
\begin{aligned}
Q^{-1}\left[\begin{array}{c}
\pi_{t} \\
E_{t} \pi_{t+1}
\end{array}\right] & =Q^{-1}\left(Q \Theta Q^{-1}\right)\left[\begin{array}{c}
\pi_{t-1} \\
E_{t-1} \pi_{t}
\end{array}\right]+Q^{-1} A^{-1}\left[\begin{array}{cc}
\frac{\lambda}{(1+\lambda)} & 0 \\
0 & 1
\end{array}\right]\left[\begin{array}{c}
v_{t}^{\pi} \\
\omega_{t}
\end{array}\right] \\
Z_{t+1} & =\Theta Z_{t}+\varsigma_{t},
\end{aligned}
$$

where $Z_{t}=Q^{-1}\left[\begin{array}{c}\pi_{t} \\ E_{t} \pi_{t+1}\end{array}\right]$ and $\varsigma_{t}=Q^{-1} A^{-1}\left[\begin{array}{cc}\frac{\lambda}{(1+\lambda)} & 0 \\ 0 & 1\end{array}\right]\left[\begin{array}{c}v_{t}^{\pi} \\ \omega_{t}\end{array}\right]$.

The solution can be written in decoupled form as:

$$
\left[\begin{array}{l}
Z_{t+1}^{s} \\
Z_{t+1}^{u}
\end{array}\right]=\left[\begin{array}{ll}
\theta^{s} & 0 \\
0 & \theta^{u}
\end{array}\right]\left[\begin{array}{c}
Z_{t}^{s} \\
Z_{t}^{u}
\end{array}\right]+\left[\begin{array}{c}
\varsigma_{t}^{s} \\
\varsigma_{t}^{u}
\end{array}\right]
$$

where

$$
\begin{aligned}
Z_{t}^{s} & =\frac{\theta^{u}}{\theta^{u}-\theta^{s}} \pi_{t}-\frac{1}{\theta^{u}-\theta^{s}} E_{t} \pi_{t+1} \\
Z_{t}^{u} & =-\frac{\theta^{s}}{\theta^{u}-\theta^{s}} \pi_{t}+\frac{1}{\theta^{u}-\theta^{s}} E_{t} \pi_{t+1} \\
\varsigma_{t}^{s} & =\frac{\lambda}{(1+\lambda)} \frac{\left(\theta^{s}+\theta^{u}\right)-1}{\left(\theta^{u}-\theta^{s}\right)} v_{t}^{\pi}-\frac{\theta^{s}-1}{\theta^{u}-\theta^{s}} \omega_{t} \\
\varsigma_{t}^{u} & =-\frac{\lambda}{(1+\lambda)} \frac{\left(\theta^{s}+\theta^{u}\right)-1}{\left(\theta^{u}-\theta^{s}\right)} v_{t}^{\pi}+\frac{\theta^{u}-1}{\theta^{u}-\theta^{s}} \omega_{t} .
\end{aligned}
$$

The stable block is iterated backwards to derive the stability conditions for the predetermined variables $Z^{s}$ :

$$
Z_{t+1}^{s}=\theta^{s} Z_{t}^{s}+\zeta_{t}^{s}=\sum_{j=0}^{\infty}\left(\theta^{s}\right)^{j} \zeta_{t-j}^{s}
$$

so it can be iterated backwards only if the eigenvalues in $\theta^{s}$ lie inside the unit circle.

The unstable block can be iterated forward to give the set of stability condition for $Z$ :

$$
E_{t} Z_{t}^{u}=\frac{1}{\theta^{u}} E_{t} Z_{t+1}^{u}=\left(\frac{1}{\theta^{u}}\right)^{n} E_{t} Z_{t+n}^{u}
$$


If the roots lie outside the unit circle then $\lim _{n \rightarrow \infty}\left(\frac{1}{\theta^{u}}\right)^{n}=0$ which implies $Z_{t}^{u}=0$ and from (C.9):

$$
\frac{\theta^{s}}{\left(\theta^{u}-\theta^{s}\right)} \pi_{t}-\frac{1}{\theta^{u}-\theta^{s}} E_{t} \pi_{t+1}=0
$$

hence $E_{t} \pi_{t+1}=\theta^{s} \pi_{t}$. Using this result and the definition of $Z_{t}^{s}$ from (C.9) it follows that $Z_{t}^{s}=\pi_{t}$.

Given the definition of $Z_{t+1}^{u}$ in (B.8) if $Z_{t}^{u}=0$ it must also be $\varsigma_{t}^{u}=0$ which from (C.9) implies:

$$
\omega_{t}=\frac{\lambda}{(1+\lambda)}\left(1+\frac{\theta^{s}}{\theta^{u}-1}\right) v_{t}^{\pi} .
$$

Knowing that $Z_{t}^{s}=\pi_{t}$, considering the definition of $\varsigma_{t}^{s}$ from (C.9) and the relationship between $\omega_{t}$ and $v_{t}^{\pi}$ as derived in (C.13), the solution for inflation is:

$$
\begin{aligned}
Z_{t+1}^{s} & =\theta^{s} Z_{t}^{s}+\varsigma_{t}^{s} \\
\pi_{t} & =\theta^{s} \pi_{t-1}+\frac{\lambda}{(1+\lambda)} \frac{\left(\theta^{s}+\theta^{u}\right)-1}{\left(\theta^{u}-\theta^{s}\right)} v_{t}^{\pi}-\frac{\theta^{s}-1}{\theta^{u}-\theta^{s}} \omega_{t} \\
\pi_{t} & =\theta^{s} \pi_{t-1}+\frac{\lambda}{(1+\lambda)}\left(1+\frac{\theta^{s}}{\theta^{u}-1}\right) v_{t}^{\pi} .
\end{aligned}
$$

